\title{
Calcium and copper transport ATPases: analogies and diversities in transduction and signaling mechanisms
}

\author{
Giuseppe Inesi
}

Received: 23 March 2011 / Accepted: 28 April 2011 /Published online: 9 June 2011

(C) The Author(s) 2011. This article is published with open access at Springerlink.com

\begin{abstract}
The calcium transport ATPase and the copper transport ATPase are members of the P-ATPase family and retain an analogous catalytic mechanism for ATP utilization, including intermediate phosphoryl transfer to a conserved aspartyl residue, vectorial displacement of bound cation, and final hydrolytic cleavage of Pi. Both ATPases undergo protein conformational changes concomitant with catalytic events. Yet, the two ATPases are prototypes of different features with regard to transduction and signaling mechanisms. The calcium ATPase resides stably on membranes delimiting cellular compartments, acquires free $\mathrm{Ca}^{2+}$ with high affinity on one side of the membrane, and releases the bound $\mathrm{Ca}^{2+}$ on the other side of the membrane to yield a high free $\mathrm{Ca}^{2+}$ gradient. These features are a basic requirement for cellular $\mathrm{Ca}^{2+}$ signaling mechanisms. On the other hand, the copper ATPase acquires copper through exchange with donor proteins, and undergoes intracellular trafficking to deliver copper to acceptor proteins. In addition to the cation transport site and the conserved aspartate undergoing catalytic phosphorylation, the copper ATPase has copper binding regulatory sites on a unique $\mathrm{N}$-terminal protein extension, and has also serine residues undergoing kinase assisted phosphorylation. These additional features are involved in the mechanism of copper ATPase intracellular trafficking which is required to deliver copper to plasma membranes for extrusion, and to the trans-Golgi network for incorporation into metalloproteins.
\end{abstract}

G. Inesi $(\bowtie)$

California Pacific Medical Center Research Institute,

475 Brannan Street,

San Francisco, CA 94107, USA

e-mail: ginesi@cpmcri.com
Isoform specific glyocosylation contributes to stabilization of ATP7A copper ATPase in plasma membranes.

Keywords Transport ATPases $\cdot \mathrm{Ca}^{2+}$ ATPase .

$\mathrm{Cu}^{2+}$ ATPase $\cdot \mathrm{Ca}^{2+}$ signaling $\cdot$ Copper trafficking .

Energy transduction
Abbreviations
NMBD N-methyl-terminus domain
SERCA Sarco-endoplasmic reticulum $\mathrm{Ca}^{2+}$ ATPase
TMBS Transmembrane binding site

\section{Introduction}

Transport ATPases of the P-type family are members of the acid dehalogenases superfamily (Burroughs et al. 2006), and are membrane bound enzymes whose catalytic cycle includes ATP utilization by formation of a phosphorylated enzyme intermediate, vectorial displacement of bound cation, and final hydrolytic cleavage of $\mathrm{Pi}$ from the phosphoenzyme intermediate. Transport ATPases (Inesi and Nakamoto 2008) are essential components of numerous mechanisms pertinent to signaling, homeostasis and energy metabolism. They are also relevant to diseases of cardiac muscle, cancer, osteoporosis, retinal degeneration, immune deficiency, cystic fibrosis, diabetes, gastric ulcer, hearing loss, skin alterations, and copper-related disorders. Compounds of pharmacological and therapeutic interest, and their interaction with transport ATPases, such as ouabain, thapsigargin and gastric $\mathrm{H}^{+}$pump inhibitors, have been recognized. Furthermore, an important role of transport 
ATPases in the establishment of drug resistance has become apparent.

Within the wide family of ion-motive P-type ATPases, it is interesting to compare the calcium and the copper transport ATPases, as they are prototypes of enzymes that retain basic structural and catalytic features, but at the same time display prominently diverse features. In fact, the plasma (Brini and Carafoli 2009) and intracellular $\mathrm{Ca}^{2+}$ ATPases (de Meis and Vianna 1979; Inesi 1985; Møller et al. 2010) reside on membranes delimiting distinct cellular compartments and, in this rather stable position, collect free $\mathrm{Ca}^{2+}$ from one side of the membrane to release it on the other side, yielding a three to four orders of magnitude free $\mathrm{Ca}^{2+}$ gradient. On the other hand, copper is acquired by the copper ATPase (Lutsenko et al. 2007) through exchange with donor proteins, and is then delivered to acceptor proteins by vectorial displacement, without formation of high free copper gradients. In addition, the copper ATPase undergoes intracellular trafficking to reach rather distant locations for copper delivery and extrusion.

\section{The calcium ATPase}

Calcium ATPases include transporters located on plasma membranes (PMCA: Brini and Carafoli 2009), on the Golgi/secretory pathway $\left(\mathrm{Ca}^{2+} / \mathrm{Mn}^{2+}\right.$-SPCA: Ton and Rao 2004; Van Baelen et al. 2004), and on Sarco-Endoplasmic Reticulum membranes (SERCA). The latter is discussed here due to its detailed characterization. SERCA enzyme isoforms are encoded by three highly conserved genes (SERCA1, 2, and 3) localized on different chromosomes, and undergo alternative splicing following transcription (Periasamy and Kalyanasundaram 2007). The SERCA1 isoform (MacLennan et al. 1985) has been studied in detail, and the sequence of reactions and conformational changes comprising its catalytic and transport cycle is well known. Its amino acid sequence comprises (Fig. 1) ten transmembrane mostly helical segments, where the fourth, fifth, sixth and eighth segments contribute residues to a Transmembrane Binding Site (TMBS) for two $\mathrm{Ca}^{2+}$ required for enzyme activation and undergoing active transport. The SERCA1 headpiece includes an $\mathbf{N}$ domain with the ATP binding site, a $\mathbf{P}$ domain with the aspartyl residue undergoing phosphorylation as a catalytic intermediate, and an $\mathbf{A}$ domain containing the conserved TGE motif involved in catalytic assistance of the final hydrolytic reaction.

From the functional stand point, the equilibrium binding isotherm (Inesi et al. 1980) shown in Fig. 2 demonstrates that each molecule of SERCA1 protein binds two $\mathrm{Ca}^{2+}$ with high affinity $\left(\mathrm{Ka}=3 \times 10^{12} \mathrm{M}^{2}\right)$ and high cooperativity (Hill coefficient $=1$.82). Mutational analysis has demonstrated that E309, E771, N796, T799, D800 and E908 in the transmembrane region (Fig. 1) are specifically required for $\mathrm{Ca}^{2+}$ dependent catalytic functions (Clarke et al. 1989; Andersen and Vilsen 1992), and are directly involved in $\mathrm{Ca}^{2+}$ binding (Strock et al. 1998) as elegantly shown by crystallography (Toyoshima et al. 2000).

The high specificity of the SERCA activating and transport sites (TMBS) for $\mathrm{Ca}^{2+}$ is revealed by high binding affinity and selectivity for $\mathrm{Ca}^{2+}$ in the presence of much higher concentrations of $\mathrm{Mg}^{2+}$ which is required in conjunction with ATP for phosphoryl transfer at the catalytic site within the $\mathrm{P}$ domain. It is of interest that $\mathrm{Mn}^{2+}$ appears able to substitute to some extent for both $\mathrm{Ca}^{2+}$ and $\mathrm{Mg}^{2+}$ (Chiesi and Inesi 1981).

Addition of ATP (Fig. 2) to the calcium activated ATPase $\left(\mathrm{E} 1 \mathrm{Ca}_{2}\right)$ is rapidly followed by formation of the phosphor-
Fig. 1 Two-dimensional folding model of the SERCA1 sequence. The diagram shows ten transmembrane segments including the calcium binding sites (TMBS) involved in enzyme activation and transport. Yellow residues contribute side chain oxygen atoms for calcium binding. The extramembranous region comprises: a nucleotide binding domain $(\mathrm{N})$; the $\mathrm{P}$ domain, with several residues (in red) conserved in P-type ATPases, including D351 that undergoes phosphorylation to form the catalytic phosphoenzyme intermediate (EP); and the A domain with the TGE conserved sequence involved in catalytic assistance of EP hydrolytic cleavage

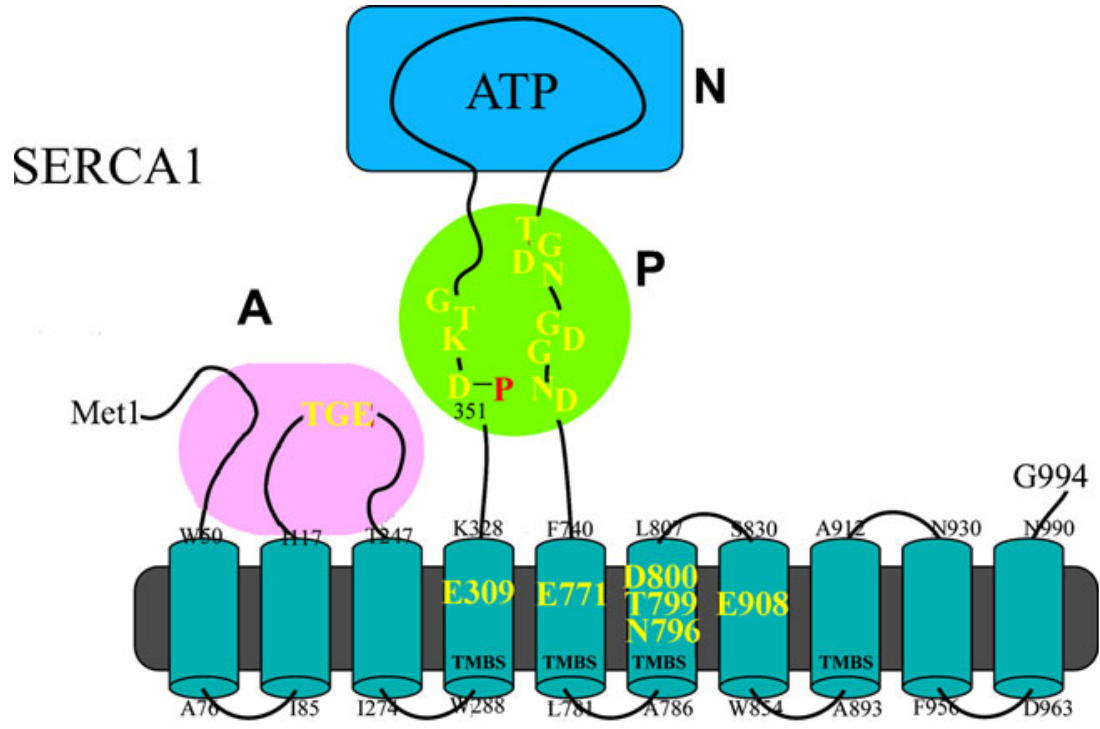




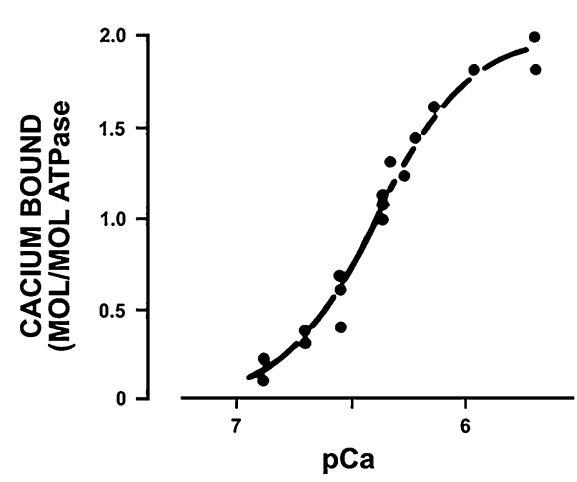

Fig. 2 Functional characterization of SERCA1. The left panel shows an equilibrium binding isotherm obtained by incubation of SERCA with different concentrations of $\mathrm{CaCl}_{2}$ (EGTA-Ca buffer) in the absence of ATP. The right panel shows a pre-steady state experiment initiated by addition of ATP to SERCA saturated with $\mathrm{Ca}^{2+}$. Rapid

ylated intermediate (E1-P $\left.\cdot \mathrm{Ca}_{2}\right)$ and occlusion of the two bound $\mathrm{Ca}^{2+}$ that become unavailable for exchange on the surface of the membrane (Inesi et al. 1980). Isomerization of the phosphoenzyme (E2-P $\left.\cdot \mathrm{Ca}_{2}\right)$ is then followed by vectorial dissociation of the two bound $\mathrm{Ca}^{2+}$. Final hydrolytic cleavage of $\mathrm{Pi}$ completes the cycle, yielding a turnover of $2 \mathrm{Ca}^{2+}$ pumped per one ATP utilized by the ATPase. At neutral $\mathrm{pH}, \mathrm{Ca}^{2+}$ binding and dissociation occur in concomitance with $\mathrm{H}^{+}$exchange, as occupancy of pertinent acidic residues favors the E2 conformation, and $\mathrm{H}^{+}$dissociation favors the $\mathrm{E} 1$ state. It is apparent that a $\mathrm{pK}$ change, in parallel with phosphoenzyme isomerization, contributes to reduction in affinity and dissociation of bound $\mathrm{Ca}^{2+}$ (Tadini-Buoninsegni et al. 2006). The sequential reactions comprising the catalytic and transport cycle are shown in the following scheme:

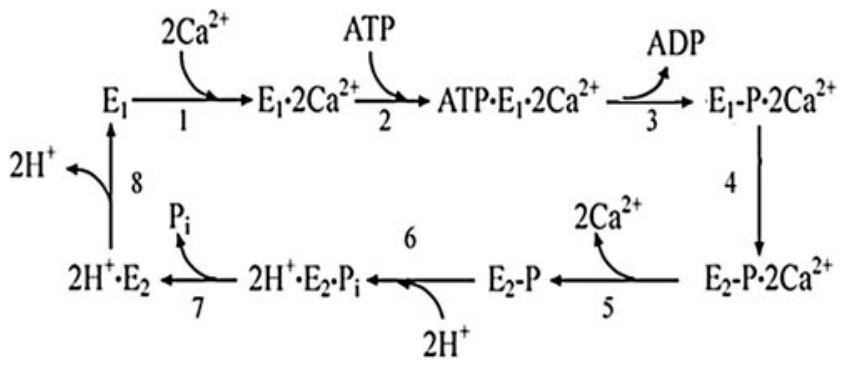

The equilibrium constants of the partial reactions listed in the scheme yield an overall free energy requirement that matches the standard free energy derived from hydrolytic cleavage of ATP $\gamma$-phosphate (Inesi et al. 1990). It is of interest that the equilibrium constants for enzyme phosphorylation by ATP (reaction 2), as well as the final hydrolytic cleavage of $\mathrm{Pi}$ (reaction 6) are nearly 1, indicating that the free energy of ATP is conserved by the enzyme and used to change the $\mathrm{Ca}^{2+}$ binding characteristics

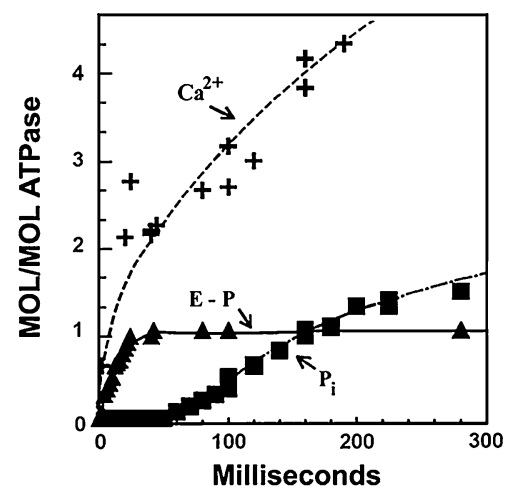

formation of phosphorylated intermediate is accompanied by occlusion of bound calcium. Hydrolytic cleavage of Pi occurs following a lag period and continues with steady state velocity. ATP utilization and $\mathrm{Ca}^{2+}$ transport occur with stoichiometric ratio of 1:2. Adapted from Inesi et al. (1980)

through conformational work. This means that the chemical potential of ATP does not manifest itself in the phosphoryl transfer (ATP $\cdot \mathrm{E} \cdot \mathrm{Ca}_{2} \longleftrightarrow$ ADP $\cdot$ E-P $\cdot \mathrm{Ca}_{2}$ ) or hydrolytic cleavage $\left(\mathrm{H}_{2} \mathrm{E}-\mathrm{P} \longleftrightarrow \longrightarrow \mathrm{H}_{2} \mathrm{E} \cdot \mathrm{Pi}\right)$ reactions, but rather in the drastic reduction of the enzyme affinity for $\mathrm{Ca}^{2+}$, as the enzyme transitions from $\mathrm{E} \cdot \mathrm{Ca}_{2}$. to $\mathrm{E} 2-\mathrm{P} \cdot \mathrm{Ca}_{2}$. If we consider that the free energy required for one ATPase cycle is used to change the equilibrium constant of reaction 1 to the equilibrium constant of reaction 4 , under standard conditions,

$\Delta G=R T \ln \left(K_{a}^{\text {reaction } 5} / K_{a}^{\text {reaction } 1}\right)$

where $K_{a}^{\text {reaction } 1}$ is the association constants of the enzyme for $\mathrm{Ca}^{2+}$ in the ground state $\left(\mathrm{H}_{2} \mathrm{E}+2 \mathrm{Ca}_{\text {out }}{ }^{2+} \longleftrightarrow \mathrm{E} \cdot \mathrm{Ca}_{2}+\right.$ $\left.2 \mathrm{H}_{\text {out }}{ }^{+}\right)$and and $K_{a}^{\text {reaction } 5}$ is the association constant of the enzyme for $\mathrm{Ca}^{2+}$ following the phosphoenzyme transition $\left(\mathrm{H}_{2} \mathrm{E}-\mathrm{P}+2 \mathrm{Ca}_{\mathrm{in}}{ }^{2+} \longleftrightarrow \mathrm{E}-\mathrm{P} \cdot \mathrm{Ca}_{2}+2 \mathrm{H}_{\text {in }}{ }^{+}\right)$. The corresponding values, at $25^{\circ} \mathrm{C}$ and $\mathrm{pH} 7.0$, are $3 \times 10^{12} \mathrm{M}^{2}$ and $3 \times 10^{5} \mathrm{M}^{2}$, yielding a free energy requirement of $\sim 9 \mathrm{Kcal}$ per cycle which is used to change $K_{a}^{\text {reaction } 1}$ to $K_{a}^{\text {reaction } 5}$. This value approximates the expected yield of free energy by cleavage of ATP $\gamma$-phosphate under standard conditions. Free energy changes in the presence of various concentrations of substrates and products were subjected to analysis and explained elsewhere (Inesi et al. 1990). It is of interest that the entire cycle can be reversed by phosphorylating the enzyme with $\mathrm{Pi}$ in the absence of $\mathrm{Ca}^{2+}$, and then adding high (mM) $\mathrm{Ca}^{2+}$ and ADP to form ATP (Masuda and de Meis 1973). Therefore, chemical and binding energy can be interconverted in either direction of the cycle, by means of protein conformational work.

Functional characterization of the SERCA cycle indicates that the basic coupling mechanism of catalysis and transport consists of mutual destabilization of $\mathrm{Ca}^{2+}$ and phosphorylation sites. Considering that the $\mathrm{Ca}^{2+}$ binding 
and phosphorylation site are separated by a relatively large distance ( $\sim 50$ A: Figs. 1 and 3$)$, it is apparent that interconversion of cation-binding and phosphorylation potentials requires a long-range intramolecular linkage, rendered possible by protein conformational changes. To start with, catalytic activation by $\mathrm{Ca}^{2+}$ binding produces a prominent conformational change, as apparent by comparing (Fig. 3) the three-dimensional structure of SERCA1 in the absence of $\mathrm{Ca}^{2+}$ (commonly referred to as E2) and in the presence of bound $\mathrm{Ca}^{2+}$ (commonly referred to E1. $\mathbf{C a}_{2}$ ). In fact, calcium binding to the TMBS affects the $\mathbf{A}, \mathbf{N}$ and $\mathbf{P}$ domain positions in the headpiece, as well as transmembrane segments. Further conformational changes occur in parallel with subsequent sequential reactions, including rotation and bending of entire domains as well as changes in orientation of side chains involved in catalysis and binding. This explains the linkage of phosphoenzyme isomerization to vectorial displacement of bound $\mathrm{Ca}^{2+}$ (Toyoshima and Inesi 2004).

A cogent demonstration of the interdependence of $\mathrm{Ca}^{2+}$ binding, protein conformational change and enzyme activation is provided by thapsigargin (TG), a very high affinity and specific inhibitor of $\mathrm{Ca}^{2+}$ binding and SERCA activation (Sagara and Inesi 1991). It is shown in Fig. 4 that the presence of TG within the SERCA transmembrane region produces steric interference (Xu et al. 2004) with displacement of the Phe256 side chain, which is normally associated with $\mathrm{Ca}^{2+}$ binding. Transition from $\mathbf{E 2}$ to $\mathbf{E 1} \cdot \mathbf{C a}_{2}$ is thereby prevented, with consequent stabilization of the E2 conformation, and loss of catalytic activity. It is noteworthy that single mutations of Phe 256 interfere with the inhibitory effect of TG (Fig. 5).

SERCA is a prominent intracellular protein of muscle, where it sustains ATP dependent $\mathrm{Ca}^{2+}$ transport across the sarcoplasmic reticulum membrane which, in concomitance

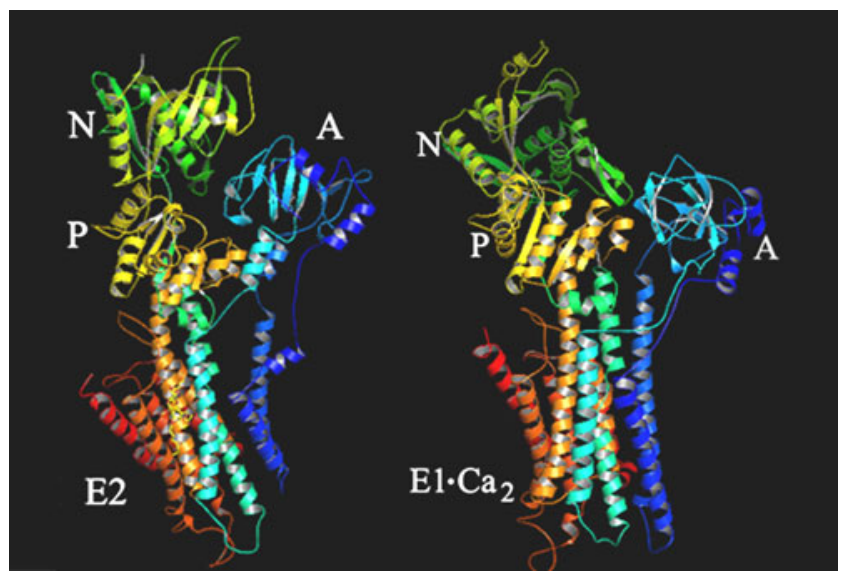

Fig. 3 Crystallographic models of SERCA1 in the E2 (left panel) and $\mathrm{E} 1 . \mathrm{Ca}_{2}$ (right panel) states. The E2 state, stabilized with thapsigargin, was derived from Protein Data Bank code 1iw0, and the E1.Ca 2 state was derived from Protein Data Bank code 1su4

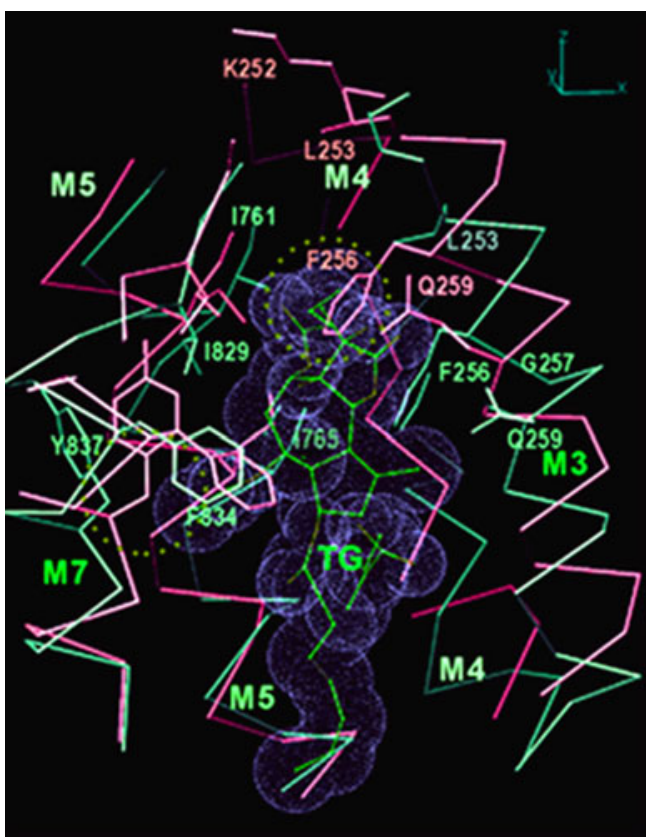

Fig. 4 Binding of thapsigargin (TG) to SERCA interferes with the E2 to $\mathrm{E} 1 . \mathrm{Ca}_{2}$ transition. TG is shown with van der Waals surface represented by dotted spheres. Transmembrane portions of M3, M4, $\mathrm{M} 5$, and $\mathrm{M} 7$ helices are in violet $\left(\mathrm{E} 1 \cdot 2 \mathrm{Ca}^{2+}\right)$ and in light green (E2 (TG)) and superimposed. Note how steric collisions (dotted circle) with TG would occur if the F256 side chain would transition from the $\mathrm{E} 2$ state to the $\mathrm{E} 1 \cdot 2 \mathrm{Ca}^{2+}$ state in the presence of TG. Derived from Xu et al. (2004)

with passive release through gated channels, allows variations of cytosolic $\mathrm{Ca}^{2+}$ concentrations and control of $\mathrm{Ca}^{2+}$ signaling functions (Clapham 2007). A clear example of the SERCA role in $\mathrm{Ca}^{2+}$ signaling is observed in cardiac myocytes (Fig. 6) where specific SERCA inhibition with TG produces a prominent reduction of $\mathrm{Ca}^{2+}$ released upon electrical stimulation, as well as slowing of the decay phase

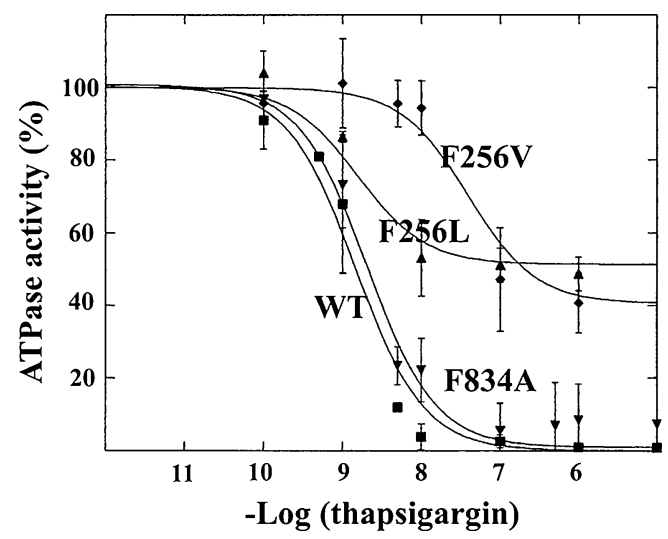

Fig. 5 Interference of Phe256 mutations with the inhibitory effect of TG on SERCA1 ATPase activity. Site directerd mutations were obtained by expression of mutated cDNA delivered by viral vectors to COS-1 cells. Experiments on ATPase activity were conducted with the microsomal fraction of the COS-1 cells sustaining heterologous expression. Derived from Xu et al. (2004) 
of the $\mathrm{Ca}^{2+}$ signal (Prasad and Inesi 2009). This indicates that $\mathrm{Ca}^{2+}$ pumping by SERCA is required to fill the $\mathrm{Ca}^{2+}$ stores to provide sufficient $\mathrm{Ca}^{2+}$ for subsequent for release to activate contraction, and is also required for removal of cytosolic $\mathrm{Ca}^{2+}$ to allow decay of the $\mathrm{Ca}^{2+}$ signal and relaxation of contraction. It is also shown in Fig. 6 that heterologous expression of additional SERCA protein by gene transfer, does not increase the amount of $\mathrm{Ca}^{2+}$ released, but increases the decay rate of the signal (Cavagna et al. 2000). This demonstrates that endogenous SERCA is sufficient to fill the $\mathrm{Ca}^{2+}$ stores for release of maximal $\mathrm{Ca}^{2+}$ upon electric stimuli, but the level of endogenous SERCA is rate limiting for the $\mathrm{Ca}^{2+}$ signal decay, which can be accelerated by expression of additional SERCA. Regulation of SERCA2 activity and level plays important roles in cardiac physiology and pathology (Bers 2008; Prasad and Inesi 2010). It is of interest that the SERCA affinity for $\mathrm{Ca}^{2+}$ and its catalytic turnover can be modulated through phosphorylation of the small partner protein phospholamban, in connection with adrenergic mechanisms in cardiac muscle (MacLennan and Kranias 2003). Generally, as mentioned above, the transduction features of $\mathrm{Ca}^{2+}$ transport ATPases are basic components of $\mathrm{Ca}^{2+}$ signaling mechanisms in numerous and diverse cell systems.

\section{The copper ATPase}

The mammalian copper ATPases ATP7A (Dierick et al. 1995; Tümer et al. 1995) and ATP7B (Petrukhin et al. 1994) encode enzyme isoforms that sustain active transport of copper by utilization of ATP, and are involved in copper transfer from enterocytes to blood, copper export from the liver, copper delivery to the secretory pathways for incorporation in metalloprotein, and general copper homeo-

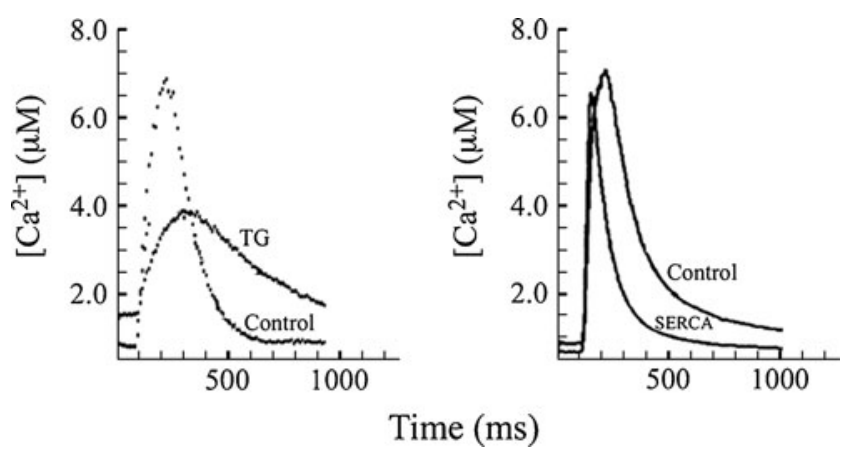

Fig. 6 Effects of thapsigargin (TG) and heterologous SERCA expression (SERCA) on cytosolic $\mathrm{Ca}^{2+}$ transients of cardiac myocytes subjected to electrical field stimulation. Myocytes treated with TG $(10 \mathrm{nM})$ or overexpressing exogenous SERCA following gene transfer by adenovirus vectors, are compared with control myocytes. Note the reduction in peak height and decay rate following TG treatment, and the inreased decay rate following SERA overexpression. Adapted from Prasad and Inesi (2009) and Cavagna et al. (2000) stasis as reviewed in detail by Lutsenko et al. (2007). Genetic defects of ATP7A and ATP7B yield the human Menkes (Vulpe et al. 1993) and Wilson (Gitlin 2003; Harada 2002) diseases, respectively.

Structural and functional features of the copper ATPase proteins have been reviewed (Mercer et al. 2003; Tsivkovskii et al. 2004; Voskoboinik et al. 2001a), indicating that ATP7A and ATP7B possess a similar architecture, with considerable sequence homology but functionally significant differences. It is shown in Fig. 7 that the ATP7B isoform comprises eight transmembrane segments (as compared to ten in SERCA), including a copper binding site (TMBS) involved in catalytic activation and transport, and a headpiece including the $\mathbf{N}, \mathbf{P}$ and $\mathbf{A}$ domains with conserved catalytic motifs analogous to SERCA1. A specific feature of mammalian copper ATPases is an amino-terminal extension (NMBD) that includes six copper binding sites in addition to the TMBS (Lutsenko et al. 2007). This N-terminal extension is involved in interactions with partner proteins and sustains copper-induced and functionally relevant conformational effects (Banci et al. 2009a).

Copper binding is attributed to characteristic CPX or XPC sequences that are present also in other P1B-type ATPases involved in transport of other metals such as cadmium, zinc, lead, cobalt and silver. On the other hand, other amino acid side chains are likely to participate in transient metal coordination during transport, thereby determining metal selectivity (Argüello 2003). Although the crystal structure of the mammalian copper ATPases is not available as yet, solution structures of specifc domains have been obtained by spectroscopic methods (Banci et al. 2009b; Dmitriev et al. 2006). Furthermore, crystal structures of microbial copper ATPases headpiece domains have been obtained (Sazinsky et al. 2006a, b; Tsuda and Toyoshima 2009). Most importantly, the occurrence of conformational changes concomitant with sequential reactions of the catalytic cycle has been demonstrated by characterization of proteolytic digestion patterns under pertinent conditions (Hatori et al. 2009). This indicates that, in analogy to the calcium ATPase, copper ATPases undergo functionally related conformational changes.

The native abundance of copper ATPases is quite low and, for this reason, biochemical experimentation requires recombinant protein obtained by heterologous expression in insect or mammalian (Barnes et al. 2005; Tsivkovskii et al. 2002; Voskoboinik et al. 2001b; Pilankatta et al. 2009) cells. It has been found that the copper ATPase undergoes phosphorylation upon addition of ATP (Barnes et al. 2005; Tsivkovskii et al. 2002; Voskoboinik et al. 2001b; Hung et al. 2007; Pilankatta et al. 2011). It is very important, in this regard, to distinguish formation of the ATPase catalytic intermediate from independent kinase assisted phosphorylation. In fact, phosphorylation of ATP7B protein (Fig. 8) 


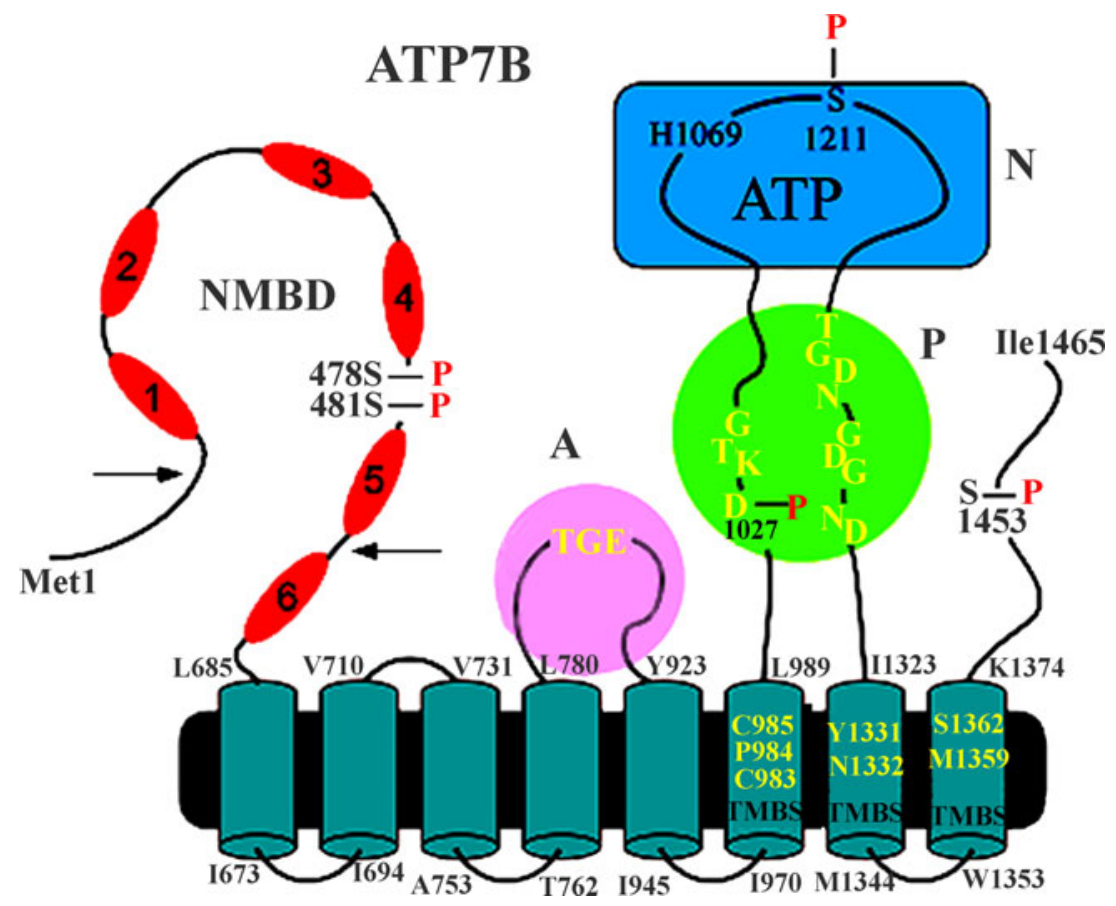

Fig. 7 Two-dimensional folding model of the ATP7B sequence. The diagram shows eight transmembrane segments including a copper binding site (TMBS). Yellow residues at the TMBS are likely involved in copper binding. The extramembranous region comprises: a nucleotide binding domain $(\mathrm{N})$ with the $\mathrm{H} 1069$ residue whose mutation is frequently found in the Wilson disease; the P domain, with several residues (in yellow) conserved in P-type ATPases, where D1027 undergoes phosphorylation to form the catalytic phosphoenzyme intermediate (EP); the A domain with the TGE (yellow) conserved sequence involved in catalytic assistance of EP hydrolytic cleavage; the $\mathrm{N}$-metal binding domain (NMBD) with six copper binding sites; and a $\mathrm{C}$-terminus chain. Serines undergoing kinase assisted phosphorylation (Ser478, Ser481, Ser1121 and Ser1453) reside within flexible loops of the protein obtained by heterologous expression in COS-1 cells includes a rapid and alkali labile component obtained within a few seconds, and a much slower alkali resistant phosphorylation (see below). Only the fast component is due to formation of phosphorylated intermediate (analogous to other P ATPases), and is not observed (Fig. 9) following mutation of the conserved aspartate (D1027) at the catalytic site, or following mutation within the transmembrane copper binding site (TMBS). Under optimal conditions, the phosphoenzyme intermediate undergoes decay by hydrolytic cleavage within the second time scale, as expected upon completion of the catalytic site.

Steady state copper transport has been observed with ATP7A expressed in cultured Chinese hamster ovary cells (Voskoboinik et al. 1998) and with reconstituted preparations of ATP7A expressed in insect cells (Hung et al. 2007), but the reported rates are much lower than expected from ATPase activity. In fact, measurements of copper transport are rendered difficult by unfavorable characteristics of the radioactive copper isotope, as well as by occurrence of non-specific high affinity copper binding. These difficulties make it impossible to obtain direct measurements of copper movements within the short time scale of a single catalytic cycle, as done in detail for the $\mathrm{Ca}^{2+}$ ATPase (Fig. 2). Nevertheless, indirect demonstration of copper movements was obtained by measurements of charge transfer upon addition of ATP to ATP7B protein adsorbed on a solid supported membrane. It is shown in Fig. 10 that, within the pre-steady state following addition of ATP, a current transient is in fact obtained, due to movement of positive charge towards the electrode. The current is not observed in the presence of copper chelators or following mutation of copper binding sites in the protein (Tadini-Buoninsegni et al. 2010). It is of interest that the decay time constant of the copper signal is $140+/-4$ milliseconds, which is significantly slower than that obtained with the $\mathrm{Ca}^{2+}$ ATPase, i.e. $25+/-$ 0.3 milliseconds under the same conditions (Fig. 10). This indicates that the catalytic and transport kinetics sustained by the copper ATPase are approximately one order of magnitude slower that those of the $\mathrm{Ca}^{2+}$ ATPase, even though the general catalytic mechanism retains similar features.

In addition to utilization of ATP for formation of phosphorylated intermediate, phosphorylation of serine residues has an influence on trafficking of ATP7A expressed in both polarized and non-polarized cells (Veldhuis et al. 2009). Furthermore, it was recently reported (Pilankatta et al. 2011) that using ATP7B protein expressed in COS-1 cells, a prominent alkali stable phosphorylation is obtained following addition of ATP. This alkali stable phosphorylation is formed at slow rates, in addition to rapid 
Fig. 8 Phosphorylation of WT ATP7B (a, b), ATP7B D1027N mutant (c) and WT SERCA1 (d), in the absence (a, c and d) and in the presence (b) of PKD inhibitor. Microsomes obtained from COS-1 cells sustaining heterologous expression of WT ATP7B (a, b), ATP7B D1027N mutant (c), or WT SERCA1 (d) were incubated with $50 \mu \mathrm{M}$ $\left[\gamma-{ }^{32} \mathrm{P}\right] \mathrm{ATP}$ at $30^{\circ} \mathrm{C}$, in the absence $(\mathbf{a}, \mathbf{c}$ and $\mathbf{d})$ or in the presence (b) of $20 \mu \mathrm{M}$ CID755673 (PKD inhibitor). Electrophoresis in acid buffer or alkaline buffer was then performed to distinguish total $\left[{ }^{32} \mathrm{P}\right]$ phosphoprotein (घ) from alkali resistant $\left[{ }^{32} \mathrm{P}\right]$ phosphoprotein ( $\square)$. The difference is considered alkali labile $\left[{ }^{32} \mathrm{P}\right]$ phosphoprotein (aspartate: $\bullet$ ) and attributed to formation of phosphorylated enzyme intermediate. The stoichiometry of phosphoprotein refers to total microsomal protein. Derived from Pilankatta et al. (2011)
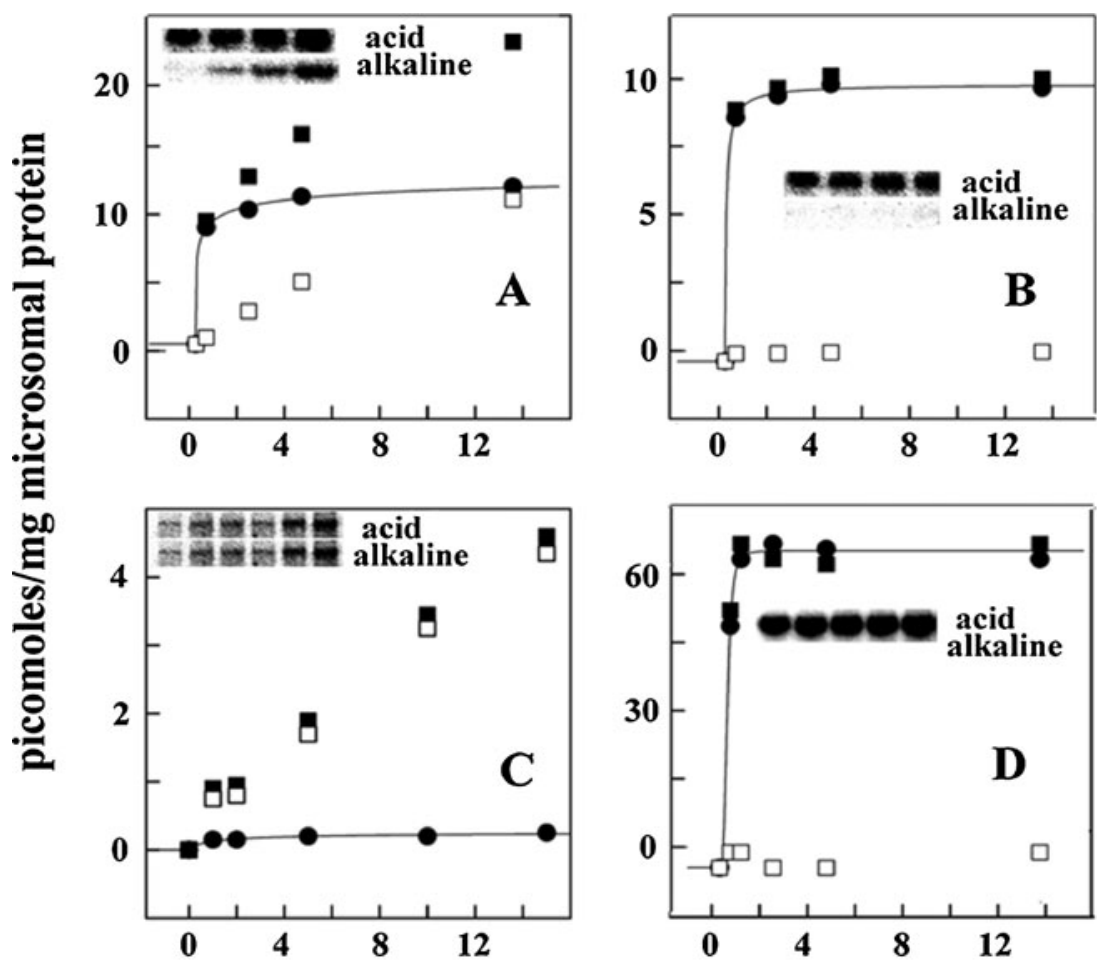

seconds formation of alkali labile phosphorylated enzyme intermediate, and is specifically and totally prevented by protein kinase D inhibition (Fig. 8). An important feature of Protein kinase $\mathrm{D}$ is its association with the trans-Golgi network, where it favors fission of transport carriers specifically destined to the cell surface (Valverde et al. 1994; Liljedahl et al. 2001). It should be noted that alkali resistant phosphorylation is not observed at all with the $\mathrm{Ca}^{2+}$ ATPase (skeletal muscle SERCA1) under the same conditions (Fig. 8). However, serine phosphorylation sustained by $\mathrm{Ca} 2+/$ calmodulindependent protein kinase has been reported for SERCA2, with consequent activation of $\mathrm{Ca}^{2+}$ pumping ATPase in cardiac and slow twitch muscle, but not in fast twitch skeletal muscle (Hawkins et al. 1994).

Alkali resistant phosphorylation of ATP7B involves serine residues at least in part identified as S478, S481, S1121 and S1453 (Fig. 7), requires copper and, most importantly, is required for ATP7B trafficking. Copper regulated movement from the Golgi apparatus to vesicles approaching the plasma membrane was first observed with ATP7A (Petris et al. 1996, 2002; La Fontaine et al. 1998), consistent with the notion that copper-induced trafficking of the copper ATPase is a key mechanism for copper homeostasis (Mercer et al. 2003). Compartmentalization and trafficking has also been observed with ATP7B (Guo et al. 2005; Schaefer et al. 1999). In fact, copper induced displacement from the trans-Golgi network to cytosolic
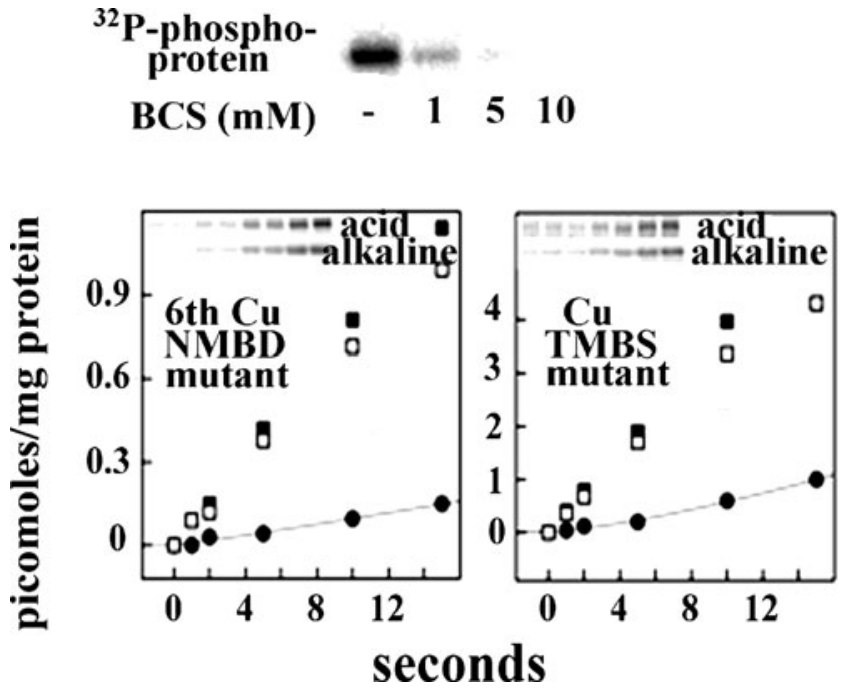

Fig. 9 Copper dependence of ATP7B phosphorylation. and effects of site directed mutations. Top: Total phosphorylation (aspartate and serines) is inhibited by copper chelation with BCS. Lower quadrants: total phosphorylation (aspartate and serines) is prevented by C575A/ C578A mutation at the 6th NMBD copper site (6thCuNMBD mutant), while only aspartate phosphorylation is prevented by C983A \& C985A mutation of the TMBS (Cu TMBS mutant). Note the different stoichiometric scale on the vertical axis of the two panels. Derived from Pilankatta et al. (2011) 


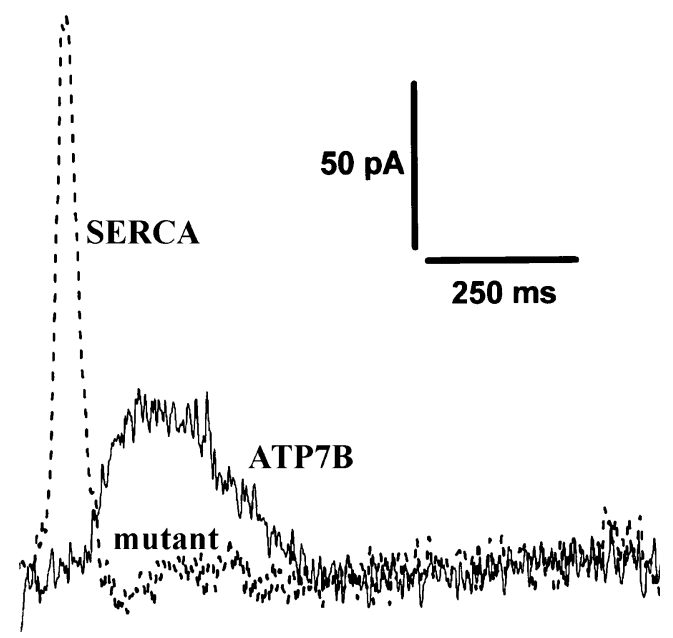

Fig. 10 Current transients obtained following rapid addition of ATP to recombinant WT copper ATPase (in the presence of $5 \mu \mathrm{M} \mathrm{CuCl}_{2}$, solid line) or $\mathrm{Ca}^{2+}$-ATPase (in the presence of $10 \mu \mathrm{M}$ free $\mathrm{Ca}^{2+}$, dotted line). Charge movements were measured with microsomes containing recombinant $\mathrm{Cu}^{+}$-ATPase (ATP7B) or $\mathrm{Ca} 2+$ ATPase (SERCA1) adsorbed on a solid supported membrane anchored to a gold electrode. No currents are obtained with an inactive ATP7B mutant. Net charge across the activated protein was compensated for by a flow of electrons along the external circuit to keep the applied voltage $\Delta V$ constant across the whole metal/solution interphase, and the resulting current transient was monitored under potentiostatic conditions as a function of time. This technique detects pre-steady state current transients within the first transport cycle, and is not sensitive to stationary currents following the first cycle. (Derived from Tadini-Buoninsegni et al. 2010)

trafficking vesicles can be shown clearly with ATP7B expressed in COS-1 cells (Fig. 11) and hepatocytes (Tsivkovskii et al. 2002). Most importantly, trafficking is not observed following mutations within the sixth copper binding site of the NMBD, or mutation of serines involved in phosphorylation assisted by protein kinase D (Pilankatta et al. 2011). It is therefore apparent that a concerted mechanism, based on copper occupancy of NMBD sites and kinase assisted phosphorylation of serines, is permissive of ATP7B trafficking. It is possible that the negative charge acquired by serines through phosphorylation, is involved in electrostatic interactions (such as arginine residues) with consequent effects on conformation and binding to partner proteins. The serine residues undergoing phosphorylation reside at rather distant locations within the TP7B sequence (Pilankatta et al. 2009), including the N terminal extension, the $\mathrm{N}$ domain and the $\mathrm{C}$ terminal. This suggests a global conformational response. In fact, a critical role of the C-terminus has been recently demonstrated (Braiterman et al. 2011). It is also important to recognize that a copper and phosphorylation dependent conformation is required to avoid degradation by proteasome mediated quality control, and to allow high levels of expressed ATP7B protein (Pilankatta et al. 2011).
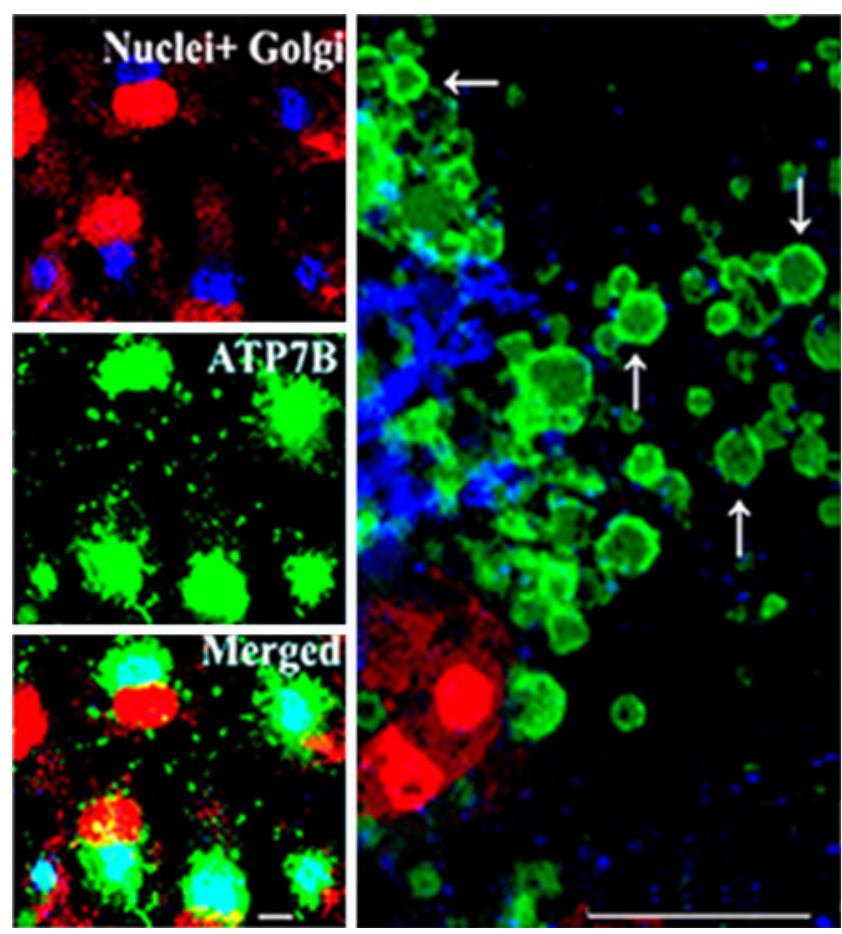

Fig. 11 Heterologous expression, distribution and trafficking of WT ATP7B in COS-1 cells. COS-1 cells were exposed overnight to $200 \mu \mathrm{M} \mathrm{CuCl} l_{2} 1$ day after infection with adenovirus vector for delivery of WT ATP7B cDNA. The cells were stained with antibodies specific for the the Golgi marker protein Giantin (left upper panel), and the ATP7B c-myc tag (left middle panel) $24 \mathrm{~h}$ following infection. Secondary antibodies yield green color for the ATP7B c-myc tag, and blue color for Golgi. Red color indicates nuclei stained with propidium iodide. The lower left panel shows merging of the stains, demonstrating colocalization of ATP7B with the Golgi marker, in a distinct and polarized location relative to the nuclei. The right panel shows an enlarged view of cytosolic vesicles containing ATP7B (green), budding from the Golgi region (blue) and trafficking throughout the cytoplasm. Bars: $15 \mu \mathrm{m}$. Derived from Pilankatta et al. (2011)

The differential effects of TMBS and NMBD copper occupancy are of special interest. Mutations within the transmembrane copper binding site (TMBS) produces specific inhibition of catalytic phosphorylation (Asp1027) in analogy to the effect of the calcium TMBS mutations in the $\mathrm{Ca}^{2+}$ ATPase. In fact, it was recently proposed that soluble copper chaperones transfer copper directly to transmembrane transport sites (González-Guerrero and Argüello 2008). Furthermore, mutation of the TMBS copper site does not interfere with kinase assisted phosphorylation of serines. On the other hand, mutation of the sixth NMBD copper site produces inhibition of both catalytic (aspartate) and kinase assisted (serines) phosphorylation (Fig. 9). It should be pointed out that a functional, global conformation of ATP7B requires the entire NMBD segment, since deletion of the segment including the first five copper NMBD sites results in extensive degradation of the expressed protein. Levels approximating those obtained 
with wild type constructs can be only obtained by specific inhibition of proteasome mediated degradation but, in this case, inactive enzyme is produced (Pilankatta et al. 2011). It is possible that, in various tissues, different requirements may be involved in conformational mechanisms to allow interactions with different partner proteins, thereby accounting for specific trafficking patterns and functions of copper ATPases. It was reported in this regard that in polarized hepatic cells, copper response and apical targeting of ATP7B is only dependent on a short segment of the $\mathrm{NH}_{2}$-extension rather than the entire NMBD (Guo et al. 2005). It was proposed that the copper-binding sites at the N-terminal domain of ATP7A are sensors of low concentrations of copper but are not essential for the overall catalytic activity (Voskoboinik et al. 2001c). Finally, specific sequence features of copper ATPases may determine diverse behaviors. For instance, the ATP7A isoform udergoes post-translational glycosylation, while the ATP7B does not ((Liu et al. 2010) and Fig. 12). This feature confers plasma membrane stabilization to the ATP7A isoform (Fig. 13).

\section{Conclusions}

Calcium and copper transport ATPases retain an analogous catalytic mechanism for utilization of ATP, but present a wide range of differences in the mechanisms of transduction and signaling. The $\mathrm{Ca}^{2+}$ ATPase is well characterized from the structural, biochemical, thermodynamic and kinetic points of view. It sustains active transport of free ion across biological membranes, providing $\mathrm{Ca}^{2+}$ concentration gradients for subsequent release of signaling $\mathrm{Ca}^{2+}$. Its conformational states are dictated by occupancy of

\section{Western Blots}

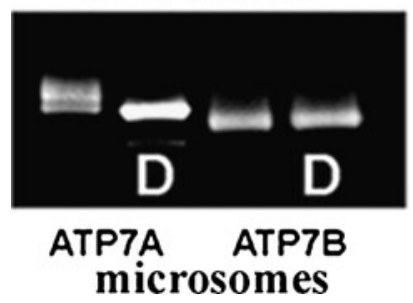

Fig. 12 Electrophoretic analysis of ATP7A or ATP7B protein derived from COS-1 cells sustaining heterologous expression of ATP7A or ATP7B and purifiedATP7A protein, and demonstration of ATP7A glycosylation. COS-1 cells were infected with viral vectors delivering cDND encoding WT ATP7A or ATP7B with a myc tag. Microsomal or purified protein stain was stained with Coomassie Blue R-250; glyocoprotein stain was obtained with Prop Q Emerald 300, and Western blots were obtained with 9E10 monoclonal antibodies against the c-myc tag in the expressed protein. D denotes samples that were subjected to deglycosylation before electrophoresis. Derived from Liu et al. (2010)
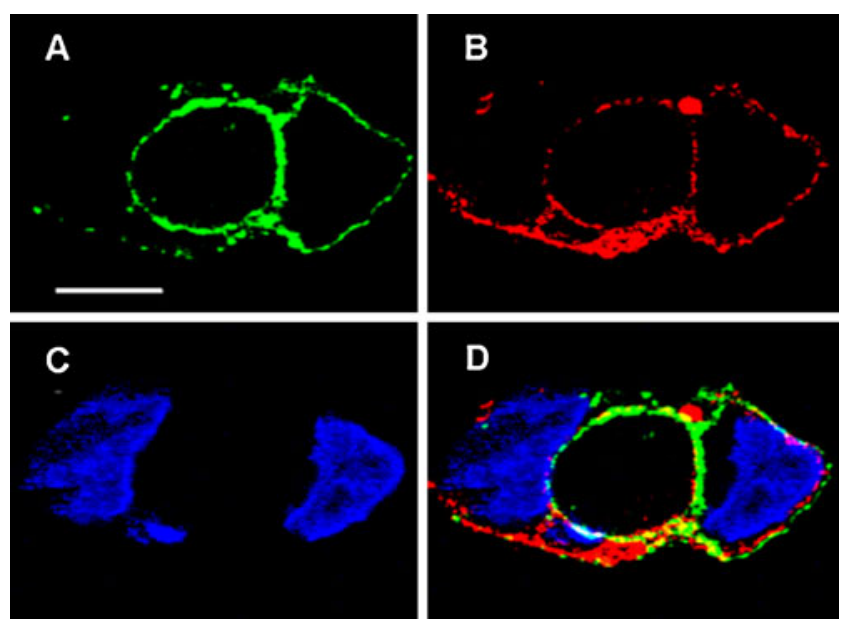

Fig. 13 Heterologous expression and association of ATP7A protein with the plasma membrane. COS- 1 cells were infected with viral vectors delivering cDND encoding WT ATP7A with a c-myc tag. $200 \mu \mathrm{M} \mathrm{CuCl} \mathrm{Cl}_{2}$ was added following the infection. After $24 \mathrm{~h}$, the cells were fixed with paraformaldehyde and permeabilized with Triton X-100. Immunostaining of ATP7A with anti-myc tag antibody is shown in green (a), and plasma membrane immunostaining with the anti-PanCadherin antibody is shown in red (b). Nuclear staining with DAPI is shown in blue (c). The overlay in panel $\mathrm{C}$ demonstrates colocalization of ATP7A and anti-Pan Cadherin antibodies in the plasma membrane. The bar is $10 \mu \mathrm{m}$. Derived from Liu et al. (2010)

calcium, nucleotide and phosphorylation sites specifically involved in catalysis and active transport. On the other hand, functionally competent conformation of the copper ATPase requires proper folding of a rather long $\mathrm{NH}_{2}$ terminal extension which is not present in the calcium ATPase. Copper occupancy of the $\mathrm{NH}_{2}$-terminal extension (NMBD) allows kinase assisted phosphorylation of serine residues and cytosolic trafficking. Occupancy of the copper TMBS and of the ATP site on the $\mathrm{N}$ domain then triggers the catalytic cycle. Copper is mostly acquired from, and delivered to partner proteins.

From a conceptual point of view, transport ATPases have been viewed as chemiosmotic pumps where ATP utilization operates, in reverse direction, the mechanism originally conceived for ATP synthesis in mitochondria (Mitchell 1961). We show here that the $\mathrm{Ca}^{2+}$ ATPase does in fact yield a chemiosmotic gradient by active transport of free $\mathrm{Ca}^{2+}$. On the contrary, the copperATPase delivers copper by active transfer from donors to acceptor proteins. Due to difficulties in measuring copper binding affinity constants, we cannot predict the extent of copper ion gradients formed by the pump. In fact, due to high binding affinity, copper ion concentrations are expected to remain low. However, we can conclude that in both calcium and copper ATPases the ATP chemical energy is utilized to produce specific protein conformational changes that affect binding affinity and orientation of specific ligands. Therefore, the common 
mechanistic feature of transport ATPases is protein conformational work, yielding in some cases an ionic gradient, and in other cases vectorial displacement of bound ligands as in the copper ATPase and, even more evidently, in drug transport ATPases (Ernst et al. 2010).

Acknowledgment The author's research is supported by National Institutes of Health Grant NHBLI RO301-69830.

Competing interests The author declares that he has no competing interests.

Open Access This article is distributed under the terms of the Creative Commons Attribution Noncommercial License which permits any noncommercial use, distribution, and reproduction in any medium, provided the original author(s) and source are credited.

\section{References}

Andersen JP, Vilsen B (1992) Functional consequences of alterations to Glu309, Glu771, and Asp800 in the $\mathrm{Ca}^{2+}$ ATPase of sarcoplasmic reticulum. J Biol Chem 267:19383-19387

Argüello JM (2003) Identification of ion-selectivity determinants in heavy-metal transport P1B-type ATPases. J Membr Biol 195:93108

Banci L, Bertini I, Cantini F, Massagni C, Migliardi M (2009a) An NMR study of the interaction of the N-terminal cytoplasmic tail of the Wilson disease protein with copper(I)-HAH1. J Biol Chem 284:9354-9360

Banci L, Bertini I, Cantini F, Migliardi M, Natile G, Nushi F, Rosato A (2009b) Solution structures of the actuator domain of ATP7A and ATP7B, the Menkes and Wilson disease proteins. Biochemistry 48:7849-7855

Barnes N, Tsivkovskii R, Tsivkovskaia N, Lutsenko S (2005) The copper-transporting ATPases, Menkes and Wilson disease proteins, have distinct roles in adult and developing cerebellum. J Biol Chem 280:9640-9645

Bers DM (2008) Calcium cycling and signaling in cardiac myocytes. Annu Rev Physiol 70:23-49

Braiterman L, Nyasae L, Leves F, Hubbard AL (2011) Critical roles for the C-Terminus of the $\mathrm{Cu}$-ATPase, ATP7B, in protein stability, trans-Golgi network retention, copper sensing and retrograde trafficking. Am J Physiol Gastrointest Liver Physiol, Mar 31. [Epub ahead of print]

Brini M, Carafoli E (2009) Calcium pumps in health and disease. Physiol Rev 89:1341-1378

Burroughs AM, Allen KN, Dunaway-Mariano D, Aravind L (2006) Evolutionary genomics of the HAD superfamily: understanding the structural adaptations and catalytic diversity in a superfamily of phosphoesterases and allied enzymes. J Mol Biol 361:1003-1034

Cavagna M, O’Donnell JM, Sumbilla C, Inesi G, Klein MG (2000) Exogenous $\mathrm{Ca}^{+}$-ATPase isoform effects on $\mathrm{Ca}^{2+}$ transients of embryonic chicken and neonatal rat cardiac myocytes. J Physiol 528:53-63

Chiesi M, Inesi $\mathrm{G}$ (1981) $\mathrm{Mg}^{2+}$ and $\mathrm{Mn}^{2+}$ modulation of $\mathrm{Ca}^{2+}$ transport and ATPase activity in sarcoplasmic reticulum vesicles. Arch Biochem Biophys 208:586-592

Clapham DE (2007) Calcium signaling. Cell 131:1047-1058

Clarke DM, Loo TW, Inesi G, MacLennan DH (1989) Location of high affinity $\mathrm{Ca}^{2+}$-binding sites within the predicted transmem- brane domain of the sarcoplasmic reticulum $\mathrm{Ca}^{2+}$ ATPase. Nature 339:476-478

de Meis L, Vianna AL (1979) Energy interconversion by the $\mathrm{Ca}^{2+}$ dependent ATPase of the sarcoplasmic reticulum. Annu Rev Biochem 48:275-292

Dierick HA, Ambrosini L, Spencer J, Glover TW, Mercer JF (1995) Molecular structure of the Menkes disease gene (ATP7A). Genomics 28:462-469

Dmitriev O, Tsivkovskii R, Abildgaard F, Morgan CT, Markley JL, Lutsenko S (2006) Solution structure of the N-domain of Wilson disease protein: distinct nucleotide-binding environment and effects of disease mutations. Proc Natl Acad Sci USA 103:5302-5307

Ernst R, Kueppers P, Stindt J, Kuchler K, Schmitt L (2010) Multidrug efflux pumps: substrate selection in ATP-binding cassette multidrug efflux pumps-first come, first served? FEBS J 277:540-549

Gitlin JD (2003) Wilson disease. Gastroenterolog 125:1868-7187

González-Guerrero M, Argüello JM (2008) Mechanism of Cu+transporting ATPases: soluble $\mathrm{Cu}^{+}$chaperones directly transfer $\mathrm{Cu}^{+}$to transmembrane transport sites. Proc Natl Acad Sci USA 105:5992-5997

Guo Y, Nyasae L, Braiterman LT, Hubbard AL (2005) NH2-terminal signals in ATP7B Cu-ATPase mediate its $\mathrm{Cu}$-dependent anterograde traffic in polarized hepatic cells. Am J Physiol 289:G904-G916

Harada M (2002) Wilson disease. Med Electron Microsc 35:61-66

Hatori Y, Lewis D, Toyoshima C, Inesi G (2009) Reaction cycle of Thermotoga maritima copper ATPase and conformational characterization of catalytically deficient mutants. Biochemistry 48:4871-4880

Hawkins C, Xu, Narayanan N (1994) Sarcoplasmic reticulum calcium pump in cardiac and slow twitch skeletal muscle but not fast twitch skeletal muscle undergoes phosphorylation by endogenous and exogenous $\mathrm{Ca} 2+/$ calmodulin-dependent protein kinase. Characterization of optimal conditions for calcium pump phosphorylation. J Biol Chem 269:31198-31206

Hung YH, Layton MJ, Voskoboinik I, Mercer JF, Camakaris J (2007) Purification and membrane reconstitution of catalytically active Menkes copper-transporting P-type ATPase (MNK; ATP7A). Biochem J 401:569-579

Inesi G (1985) Mechanism of calcium transport. Annu Rev Physiol 47:573-601

Inesi G, Nakamoto RK (2008) Special issue on transport ATPases. Arch Biochem Biophys 476:1-2

Inesi G, Kurzmack M, Coan C, Lewis DE (1980) Cooperative calcium binding and ATPase activation in sarcoplasmic reticulum vesicles. J Biol Chem 255:3025-3031

Inesi G, Sumbilla C, Kirtley ME (1990) Relationships of molecular structure and function in $\mathrm{Ca}^{2+}$ transport ATPase. Physiol Rev 70:749-760

La Fontaine S, Firth SD, Lockhart PJ, Brooks H, Parton RG, Camakaris J, Mercer JF (1998) Functional analysis and intracellular localization of the human menkes protein (MNK) stably expressed from a cDNA construct in Chinese hamster ovary cells (CHO-K1). Hum Mol Genet 7:1293-1300

Liljedahl M, Maeda Y, Colanzi A, Ayala I, Van Lint J, Malhotra V (2001) Protein kinase D regulates the fission of cell surface destined transport carriers from the trans-Golgi network. Cell 104:409-420

Liu Y, Pilankatta R, Hatori Y, Lewis D, Inesi G (2010) Comparative features of copper ATPases ATP7A and ATP7B heterologously expressed in COS-1 cells. Biochemistry 49:10006-10012

Lutsenko S, Barnes NL, Bartee MY, Dmitriev OY (2007) Function and regulation of human copper-transporting ATPases. Physiol Rev 87:1011-1046

MacLennan DH, Kranias EG (2003) Phospholamban: a crucial regulator of cardiac contractility. Nat Rev Mol Cell Biol 4:566-577

MacLennan DH, Brandl CJ, Korczak B, Green NM (1985) Aminoacid sequence of $\mathrm{a} \mathrm{Ca}^{2+}$ and $\mathrm{Mg}^{2+}$ dependent ATPase from rabbit 
muscle sarcoplasmic reticulum, deduced from its complementary DNA sequence. Nature 316:696-700

Masuda H, de Meis L (1973) Phosphorylation of the sarcoplasmic reticulum membrane by orthophosphate. Inhibition by calcium ions. Biochemistry 12:4581-4585

Mercer JF, Barnes N, Stevenson J, Strausak D, Llanos RM (2003) Copper-induced trafficking of the cU-ATPases: a key mechanism for copper homeostasis. Biometals 16:175-184

Mitchell P (1961) Coupling of phosphorylation to electron and hydrogen transfer by a chemi-osmotic type of mechanism. Nature 191:144-148

Møller JV, Olesen C, Winther AM, Nissen P (2010) The sarcoplasmic Ca2+-ATPase: design of a perfect chemi-osmotic pump. Q Rev Biophys 43:501-566

Periasamy M, Kalyanasundaram A (2007) SERCA pump isoforms: their role in calcium transport and disease. Muscle Nerve 35:430-442

Petris MJ, Mercer JF, Culvenor JG, Lockhart P, Gleeson PA, Camakaris J (1996) Ligand-regulated transport of the Menkes copper P-type ATPase efflux pump from the Golgi apparatus to the plasma membrane: a novel mechanism of regulated trafficking. EMBO J 15:6084-6095

Petris MJ, Voskoboinik I, Cater M, Smith K, Kim BE, Llanos RM, Strausak D, Camakaris J, Mercer JF (2002) Copper-regulated trafficking of the Menkes disease copper ATPase is associated with formation of a phosphorylated catalytic intermediate. J Biol Chem 277:46736-46742

Petrukhin K, Lutsenko S, Chernov I, Ross BM, Kaplan JH, Gilliam TC (1994) Characterization of the Wilson disease gene encoding a P-type copper transporting ATPase: genomic organization, alternative splicing, and structure/function predictions. Hum Mol Genet 3:1647-1656

Pilankatta R, Lewis D, Adams CM, Inesi G (2009) High yield heterologous expression of wild-type and mutant $\mathrm{Cu}+-$ ATPase (ATP7B, Wilson disease protein) for functional characterization of catalytic activity and serine residues undergoing copperdependent phosphorylation. J Biol Chem 284:21307-21316

Pilankatta R, Lewis D, Inesi G (2011) Involvement of protein kinase D in expression and trafficking of ATP7B (Copper ATPase). J Biol Chem 286:7389-7396

Prasad AM, Inesi G (2009) Effects of thapsigargin and phenylephrine on calcineurin and protein kinase $\mathrm{C}$ signaling functions in cardiac myocytes. Am J Physiol Cell Physiol 296:C992-C1002

Prasad AM, Inesi G (2010) Downregulation of $\mathrm{Ca}^{2+}$ signalling proteins in cardiac hypertrophy. Minerva Cardioangiol 58:193-204

Sagara Y, Inesi G (1991) Inhibition of the sarcoplasmic reticulum $\mathrm{Ca}^{2+}$ transport ATPase by thapsigargin at subnanomolar concentrations. J Biol Chem 266:13503-13506

Sazinsky MH, Mandal AK, Argüello JM, Rosenzweig AC (2006a) Structure of the ATP binding domain from the Archaeoglobus fulgidus $\mathrm{Cu}^{+}$ATP ase. J Biol Chem 281:11161-11166

Sazinsky MH, Agarwal S, Argüello JM, Rosenzweig AC (2006b) Structure of the actuator domain from the Archaeoglobus fulgidus $\mathrm{Cu}^{+}$ATPase. Biochemistry 45:9949-9955

Schaefer M, Hopkins RG, Failla ML, Gitlin JD (1999) Hepatocytespecific localization and copper-dependent trafficking of the Wilson's disease protein in the liver. Am J Physiol 276:G639-G646

Strock C, Cavagna M, Peiffer WE, Sumbilla C, Lewis D, Inesi G (1998) Direct demonstration of Ca2+ binding defects in sarcoendoplasmic reticulum $\mathrm{Ca}^{2+}$ ATPase mutants overexpressed in COS-1 cells transfected with adenovirus vectors. J Biol Chem 273:15104-15109

Tadini-Buoninsegni F, Bartolommei G, Moncelli MR, Guidelli R, Inesi G (2006) Pre-steady state electrogenic events of $\mathrm{Ca} 2+/ \mathrm{H}+$ exchange and transport by the $\mathrm{Ca}^{2+}$ ATPase. J Biol Chem 281:37720-37727
Tadini-Buoninsegni F, Bartolommei G, Moncelli MR, Pilankatta R, Lewis D, Inesi G (2010) ATP dependent charge movement in ATP7B $\mathrm{Cu}+-$ ATPase is demonstrated by pre-steady state electrical measurements. FEBS Lett 584:4619-4622

Ton VK, Rao R (2004) Functional expression of heterologous proteins in yeast: insights into $\mathrm{Ca}^{2+}$ signaling and $\mathrm{Ca}^{2+}$-transporting ATPases. Am J Physiol Cell Physiol 287:C580-C589

Toyoshima C, Inesi G (2004) Structural basis of ion pumping by Ca2+-ATPase of the sarcoplasmic reticulum. Annu Rev Biochem 73:269-292

Toyoshima C, Nakasako M, Nomura H, Ogawa H (2000) Structure determination of the calcium pump of sarcoplasmic reticulum. Nature 405:647-655

Tsivkovskii R, Eisses JF, Kaplan JH, Lutsenko S (2002) Functional properties of the copper-transporting ATPase ATP7B (the Wilson's disease protein) expressed in insect cells. J Biol Chem 277:976-983

Tsivkovskii R, Purnat T, Lutsenko S (2004) Copper transporting ATPases: key regulators of intracellular copper concentration. In: Futai, Kaplan, Wada (eds) Handbook of ATPases. Weiley-VCH Verlag, Weinheim, pp 99-158

Tsuda T, Toyoshima C (2009) Nucleotide recognition by CopA, a $\mathrm{Cu}+$ -transporting P-type ATPase. EMBO J 28:1782-1791

Tümer Z, Vural B, Tønnesen T, Chelly J, Monaco AP, Horn N (1995) Characterization of the exon structure of the Menkes disease gene using vectorette PCR. Genomics 26:437-442

Valverde AM, Sinnett-Smith J, Van Lint J, Rozengurt E (1994) Molecular cloning and characterization of protein kinase $\mathrm{D}$ : a target for diacylglycerol and phorbol esters with a distinctive catalytic domain. Proc Natl Acad Sci USA 91:8572-8576

Van Baelen K, Dode L, Vanoevelen J, Callewaert G, De Smedt H, Missiaen L, Parys JB, Raeymaekers L, Wuytack F (2004) The $\mathrm{Ca}^{2+} / \mathrm{Mn}^{2+}$ pumps in the Golgi apparatus. Biochim Biophys Acta 1742:103-112

Veldhuis NA, Valova VA, Gaeth AP, Palstra N, Hannan KM, Michell BJ, Kelly LE, Jennings I, Kemp BE, Pearson RB, Robinson PJ, Camakaris J (2009) Phosphorylation regulates copper-responsive trafficking of the Menkes copper transporting P-type ATPase. Int J Biochem Cell Biol 41:2403-2412

Voskoboinik I, Brooks H, Smith S, Shen P, Camakaris J (1998) ATPdependent copper transport by the Menkes protein in membrane vesicles isolated from cultured Chinese hamster ovary cells. FEBS Lett 435:178-182

Voskoboinik I, Greenough M, La Fontaine S, Mercer JF, Camakaris J (2001a) Functional studies on the Wilson copper P-type ATPase and toxic milk mouse mutant. Biochem Biophys Res Commun 281:966-970

Voskoboinik I, Mar J, Strausak D, Camakaris J (2001b) The regulation of catalytic activity of the menkes copper-translocating P-type ATPase. Role of high affinity copper-binding sites. J Biol Chem 276:28620-28627

Voskoboinik I, Jasmine Mar J, Daniel Strausak D, Camakaris J (2001c) The regulation of catalytic activity of the Menkes copper-translocating P-type ATPase the regulation of catalytic activity of the Menkes copper-translocating P-type ATPase: Role of high affinity copper-binding sites. J Biol Chem 276:28620 28627

Vulpe C, Levinson B, Whitney S, Packman S, Gitschier J (1993) Isolation of a candidate gene for Menkes disease and evidence that it encodes a copper-transporting ATPase. Nat Genet 3:7-13, Erratum in: Nat enet 1993, 3:273

$\mathrm{Xu} \mathrm{C}$, Ma H, Inesi G, Al-Shawi MK, Toyoshima C (2004) Specific structural requirements for the inhibitory effect of thapsigargin on the $\mathrm{Ca}^{2+}$ ATPase (SERCA). J Biol Chem 279:17973-17979 